\title{
Receptor cuasicoherente de 25 Gbps para redes de acceso futuras
}

\author{
Jose A. Altabas ${ }^{1}$, Lau F. Suhr ${ }^{2}$, Guillermo Silva Valdecasa ${ }^{2}$, Jose A. Lazaro ${ }^{3}$, Jesper B. \\ Jensen $^{2}$, Anders T. Clausen ${ }^{4}$, I. Garces ${ }^{1}$ \\ ${ }^{1}$ Grupo de Tecnologías Fotónicas (GTF) \\ Instituto de Investigación en Ingeniería de Aragón (I3A) \\ Universidad de Zaragoza, Mariano Esquillor s/n, 50018, Zaragoza, Spain. \\ Tel. +34-976762707, e-mail: jaltabas@unizar.es \\ ${ }^{2}$ Bifrost Communications, Scion DTU, Akademivej Bygnig 381, 2800 Kgs Lyngby, Denmark \\ ${ }^{3}$ Universitat Politècnica de Catalunya, Jordi Girona 31, 08034, Barcelona, Spain \\ ${ }^{4}$ DTU Fotonik, Technical University of Denmark (DTU), Ørsteds Plads, 2800 Kgs. Lyngby, Denmark
}

\section{Resumen}

Este articulo presenta un receptor cuasicoherente de $25 \mathrm{Gbps}$ con un DSP sencillo para redes de acceso futuras. Este receptor cuasicoherente de $25 \mathrm{Gbps}$ con decodificación duobinaria presenta una sensibilidad de $-24.7 \mathrm{dBm}$ tras la transmisión a través de $20 \mathrm{~km}$ de fibra y provee un balance de potencia de $25.7 \mathrm{~dB}$.

\section{Introducción}

Los nuevos servicios en red, el internet de las cosas (IoT), la realizad virtual y aumentada, y la convergencia entre las redes móviles y ópticas [1] están haciendo crecer el tráfico de datos sobre las redes de acceso de forma exponencial. Para poder hacer frente a esta demanda, se está desarrollando la tecnología necesaria para las futuras redes de acceso (25G-PON o 100G(4x25G)-PON). Este trabajo presenta un receptor cuasicoherente de 25 Gbps que permite incrementar la sensibilidad de los receptores, así como una operación independiente de la longitud de onda sin filtros ópticos.

\section{Montaje Experimental}

La figura 1 muestra el esquemático del receptor cuasicoherente de $25 \mathrm{Gbps}$, así como el montaje experimental utilizado para su testeo.

El receptor cuasicoherente de 25 Gbps está compuesto por un acoplador óptico, un divisor de polarización (PBS) y de dos fotodectores (PD) de $33 \mathrm{GHz}$ de ancho de banda eléctrico. La señal recibida se mezcla con el oscilador local (OL), que es un láser de cavidad externa con una potencia óptica de $14.5 \mathrm{dBm}$. Esto hace que señal recibida sea convertida a una frecuencia intermedia (IF) de $18 \mathrm{GHz}$. Estas señales de IF son convertidas a banda base mediante dos detectores de envolvente de ultra banda ancha basado en diodos Schottky diseñados para señales de $10 \mathrm{Gbps}$ y similares a los presentados en [2], tras lo cual son digitalizadas mediante un osciloscopio de $80 \mathrm{GS} / \mathrm{s}$ (DSO). Esta señal digitalizada es sometida un procesado digital de señal sencillo apto para redes ópticas de acceso. El primer paso es sumar las dos señales, obteniendo la independencia frente a fluctuaciones en la polarización de la señal recibida. Este primer paso se ha realizado en el dominio digital por simplicidad en nuestro montaje, pero podría realizarse en el dominio analógico y reducir el sistema de digitalización a único conversor analógico digital [2]. El segundo paso es aplicar un ecualizador a la señal para obtener o una señal NRZ o una duobinaria. Este ecualizador está basado en feedforward equalization (FFE) and a decision feedback equalization (DFE). Se han considerado dos ecualizadores, uno de altas prestaciones compuesto por un FFE de 41 taps y un DFE de 21 taps, y otro de baja complejidad basado en un FFE de 15 taps y un DFE de 6 taps. Finalmente, se realiza el decodificado NRZ o duobinario y se evalúa la tasa de error (BER).

El montaje experimental para probar este receptor consiste en un láser modulado externamente (EML) con una potencia óptica emitida de $+1 \mathrm{dBm}$, una ratio de extinción de $8 \mathrm{~dB}$ y una longitud de onda de $1554.44 \mathrm{~nm}$; una fibra monomodo estándar (SSMF) de $20 \mathrm{~km}$ y un atenuador óptico variable (VOA). El EML es modulado con una señal PRBS NRZ de 25 Gbps generado con generador arbitrario de señales (AWG) de $65 \mathrm{GS} / \mathrm{s}$. El sistema de modulación conjunto emula un ancho de banda eléctrico de $18 \mathrm{GHz}$.

\section{Resultados}

La sensibilidad se define como la mínima potencia óptica recibida para la que se obtiene un BER de $10^{-3}$, que es el requerido en el estándar actual NG-PON2 [3]. Las curvas de sensibilidad son mostradas en la figura 2 para decodificación NRZ y en la figura 3 para decodificación duobinaria. 
Ambas figuras muestran los resultados para ambos ecualizadores, tanto para transmisión sin fibra (BTB) como para $20 \mathrm{~km} \mathrm{SSMF.}$

La sensibilidad BTB obtenida con el ecualizador de altas prestaciones es $-30.5 \mathrm{dBm}$ con decodificación NRZ y $-28.5 \mathrm{dBm}$ con decodificación duobinaria. Este penalti se debe al nivel adicional que aparece en las señales duobinarias. La sensibilidad después de la transmisión a través de $20 \mathrm{~km}$ SSMF cae a $-24 \mathrm{dBm}$ para la decodificación NRZ y a $-24.7 \mathrm{dBm}$ para la decodificación duobinaria. Este menor penalti debido a la dispersión cromática en al decodificación duobinaria es debido al espectro reducido de este tipo de señales. Cuando el sistema requiere una menor complejidad en procesado digital de la señal, se debe utilizar el ecualizador de baja complejidad asumiendo un penalti en la sensibilidad del receptor. En este caso, la sensibilidad BTB con decodificación NRZ es de $-29.2 \mathrm{dBm}$ y con decodificación duobinaria es de $-27 \mathrm{dBm}$. Después de la transmisión a través de $20 \mathrm{~km}$ SSMF, la señal no puede decodificarse como NRZ mientras que con decodificación duobinaria se obtiene una sensibilidad de $-25 \mathrm{dBm}$.

Por lo tanto, el receptor cuasicoherente de $25 \mathrm{Gbps}$ con decodificación duobinaria y combinado con este EML puede ofrecer un balance de potencias después de la transmisión a través de $20 \mathrm{~km}$ SSMF de $25.7 \mathrm{~dB}$ con el ecualizador de altas prestaciones $\mathrm{y}$ de $23 \mathrm{~dB}$ con el ecualizador de baja complejidad. Estos balances de potencias permitirían unas ratios de reparto de 64 y 32, respectivamente. En caso de utilizar una longitud de onda en una banda con baja dispersión cromática, como puede ser la banda $\mathrm{O}$, la decodificación NRZ podría ser utilizada incrementando el balance de potencias, pero la ratio de reparto sería similar debido a la mayor atenuación de la fibra en esta banda.

\section{Conclusiones}

En conclusión, el receptor cuasicoherente de $25 \mathrm{Gbps}$ es un candidato atractivo para las redes de acceso futuras, especialmente las redes de acceso de $25 \mathrm{Gbps}$ con longitud de onda única como 25G-PON y las redes de acceso de $100 \mathrm{Gbps}$ con multilongitud de onda como 100G-PON (4x25G).

\section{REFERENCIAS}

[1]. Cisco Visual Networking Index: Global Mobile Data Traffic Forecast Update, 2016-2021, White Paper.

[2]. ALTABAS, J.A., et al. Real-time 10Gbps Polarization Independent Quasicoherent Receiver for NG-PON2 Access Networks. En: Procedings of OFC, San Diego, 2018, Th1A3.

[3]. WEY, J.S., et al. Physical layer aspects of NG-PON2 standards-Part 1: Optical link design [Invited]. En: Journal of Optical Communications and Networking. 2016, Vol. 8, no. 1, p. 33-42.
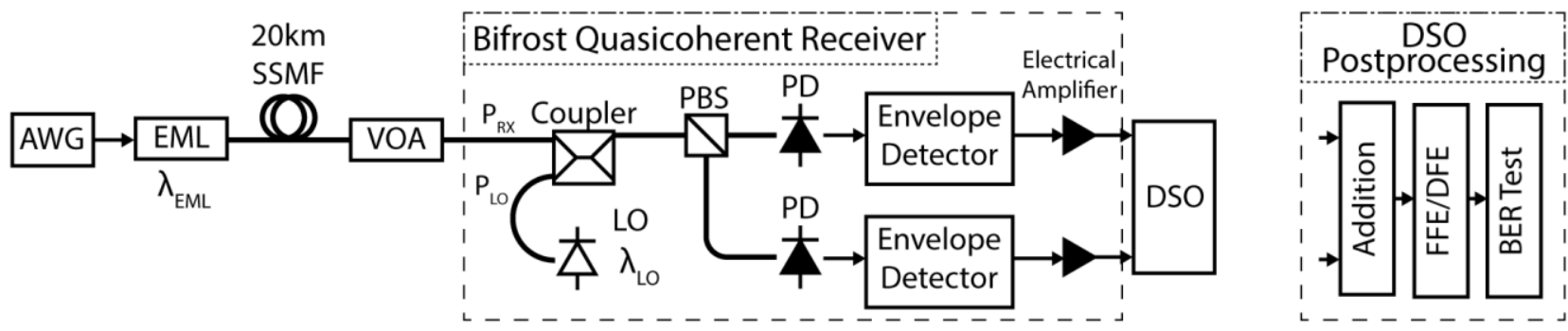

Figura 1: Montaje experimental.

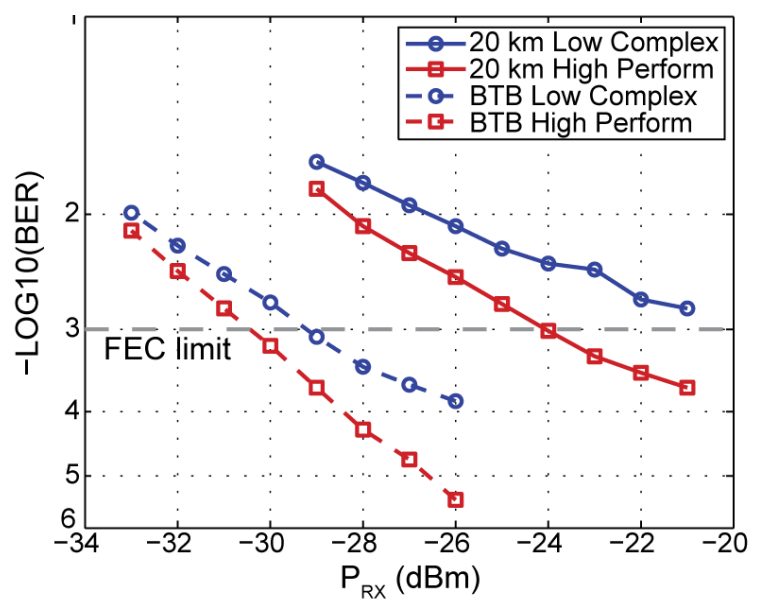

Figura 2: BER versus potencia recibida para el receptor cuasicoherente de 25 Gbps con decodificación NRZ.

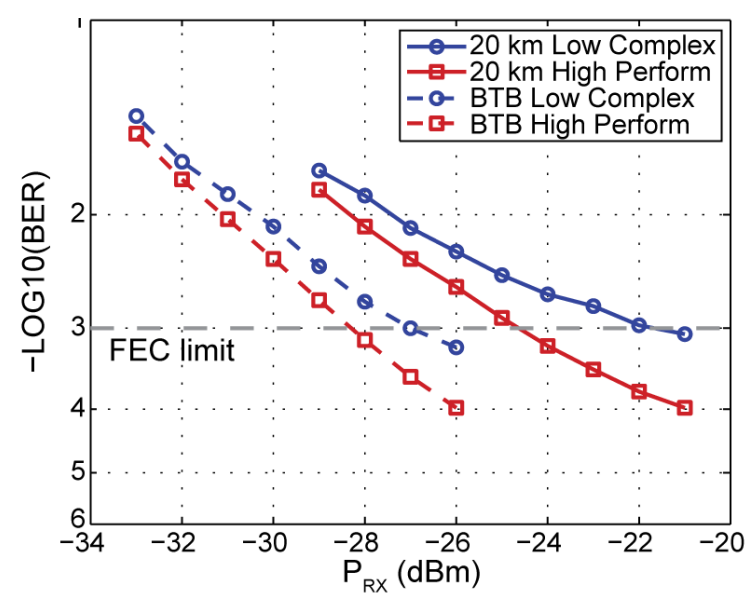

Figura 3: BER versus potencia recibida para el receptor cuasicoherente de 25 Gbps con decodificación duobinaria.

Revista "Jornada de Jóvenes Investigadores del I3A", vol. 6 (Actas de la VII Jornada de Jóvenes Investigadores del I3A - 8 de junio de 2018). ISSN 2341-4790. 